\title{
Physical, chemical, and microbiological water quality variation between city and building and within multi-story building
}

\author{
Rain Richard ${ }^{\mathrm{a}, \mathrm{b} *}$, Kerry A. Hamilton ${ }^{\mathrm{a}, \mathrm{c}}$, Paul Westerhoff ${ }^{\mathrm{a}}$, and Treavor H. Boyer ${ }^{\mathrm{a}, \mathrm{b} *}$

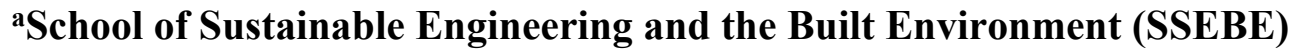 \\ bBodesign Swette Center for Environmental Biotechnology \\ 'Biodesign Center for Environmental Health Engineering \\ Arizona State University \\ PO Box 873005, Tempe, AZ 85287-3005, USA \\ *Corresponding authors \\ Treavor H. Boyer \\ Tel: 1-480-965-7447 \\ E-mail address: thboyer@asu.edu \\ Rain Richard \\ E-mail address: $\underline{\text { rain.richard@asu.edu }}$
}

SUPPLEMENTAL MATERIALS

23 Pages

1 Table

15 Figures 


\section{Experimental}

2.1 Description of the institutional building

Biodesign C (BDC) is a LEED Platinum 5-story building plus basement located at Arizona State University (ASU), Tempe, AZ. The building has 189,000 gross $\mathrm{ft} 2$ with $60,000 \mathrm{ft} 2$ dedicated to combined lab and office spaces. Except for the basement, each floor has a breakroom that includes a sink and faucet. Nearby are restrooms with a small alcove for two water fountains shown in the supporting information (SI), Figures S1-S3. The domestic cold water (DCW) 6" main starts in the basement mechanical room (Figure S5 - S7) and splits into three risers; DCW, industrial cold water (ICW) and non-potable water (NPW). All risers and plumbing material are of copper construction. Technically, the ICW and NPW risers are fed with potable water from the DCW. However, backflow prevention is required on the ICW and NPW risers because of the equipment attached to these lines. For safety reasons, the use of backflow prevention makes the water not suitable for human consumption even though the main DCW line feeding ICW and NPW is potable water, and no extra treatment has been done. Specific treatment such as deionization of water to specific lab equipment occurs on each floor, not in the mechanical room. Plumbing to the breakrooms, restrooms, and water fountains are on one riser so each floor's water fixtures are stacked above the other floor's water fixtures. This riser is labeled DCW. The lab spaces are on the ICW riser with backflow prevention. The NPW riser is not discussed in this paper as it is used for building makeup water for heating. Building construction began in June 2016 and was handed over to Arizona State University on May 1, 2018. Prior to taking ownership, on March 28, 2018, a hyperchlorination passivation event was conducted. Before hyperchlorination occurs, the premise plumbing is flushed to remove any residual plumbing debris that could become a source of contamination from the domestic water lines and hyperchlorination passivation ensures the water lines are disinfected at building hand-off. This passivation event required a chlorine residual of greater than $50 \mathrm{mg} / \mathrm{L}$ be held overnight. Occupants began moving into the building in May 2018 and continued to move into the building throughout the year-long study. The building has also been described in Richard et. al 2020.21 During construction, the DCW main in the mechanical room was outfitted with an ultrasonic flow meter. 
This meter is located immediately after the DCW main enters the basement upstream of the whole building water softeners. The ICW and NPW lines are sub-metered with the same brand ultrasonic flowmeter. The flowmeter on the DCW main measures all the DCW use in the building including ICW and NPW as they are fed by DCW. The sub-meters allow for specific monitoring. For example, the ICW

line measures lab-based equipment, instruments, sinks, and cooling towers while NPW measures makeup water for building heat. ASU Facilities Technologies Systems (FST) provided weekly reports of the ICW, NPW, and DCW demand which was measured every 15 min.

\subsubsection{Part 1}

Twice weekly, Monday and Thursday starting at 8:30 AM local time, water sampling was conducted in Biodesign $\mathrm{C}$, floors 1 through 5. The breakroom faucet cold-water side was tested on all floors. The first draw was an immediate sample of $1 \mathrm{~L}$. After the first draw, the water was flushed for 1 min after which a second draw of $1 \mathrm{~L}$ was collected. The same sampling protocol was conducted for the water fountains on each floor. The first part was during the first 6 months (May 2018-October 2018) in which 42 first draw and 42 second draw samples were collected for each floor at the breakroom sinks as well as 42 first draw and 42 second draw samples were collected for the water fountain. The naming convention for the samples is \#-B-\# or \#-W-\# where the first number represents the floor, the letter represents breakroom sinks or water fountains, and the second number represents the first or second draw. For example, 1-B-1 indicates the $1^{\text {st }}$ floor breakroom first draw.

Collection time and temperature were recorded immediately. In the lab, these samples were analyzed for $\mathrm{pH}$, conductivity, UV254, dissolved and unfiltered $\mathrm{Cu}$, and free chlorine. The Orion VersaStar Pro was used to measure $\mathrm{pH}$ and conductivity. The UV-Vis spectrophotometer Orion AquaMate 8000 was used to measure UV254, dissolved and unfiltered $\mathrm{Cu}$ and free chlorine. Dissolved and unfiltered $\mathrm{Cu}$ was measured by colorimetry by the bicinchoninate method (reagent \#AC4P29, range: $0.05-5 \mathrm{mg} / \mathrm{L}$ ), and free chlorine was measured by the DPD 
method (reagent \# ACP471, range $0.02-2 \mathrm{mg} / \mathrm{L}$ ) following the instrument instructions. Standard Method 1030C Method Detection Level was followed to determine the minimum detection level, and 3020B Quality Control Practices was followed to confirm the instrument calibration reported for the above-mentioned methods ${ }^{12}$

\subsubsection{Part 2}

The second part was the second half of the yearlong study (November 2018-April 2019), in which 34 first draw and 34 second draw samples were collected per floor for each water fountain and each breakroom sink. Again, time and temperature were recorded immediately. In the lab, these samples were measured same as the first six months in 2.2 .1 excluding $\mathrm{pH}$ and conductivity.

\subsubsection{Part 3}

Starting in late January 2019 two new sampling sites were selected. New collection point \#1 known as building inlet, was at a hose bib just past the meter where the city water tied into the building domestic water line before the water entered the basement to be processed by the whole building water softener. New collection site \#2, known as valve, was installed just past the whole building water softener prior to the water entering the risers to the breakroom and lab spaces. The building inlet and valve were incorporated into the twice weekly sampling routine as well as measuring the grab samples for TTHMs with the THM analyzer. $1 \mathrm{~L}$ of sample was collected in glass amber bottles with PTFE lined tops head space free. Sodium thiosulfate was added to the

bottle prior to collection to stop any reactions. These samples were measured same day but were put on ice until ready for analysis. Operation of the THM analyzer for grab samples was conducted following the instrument's instruction manual provided by the company (Model PHOLTHM-1000). 
Beginning February 2019 cellular adenosine triphosphate (cATP) analysis began. This water quality parameter was conducted for the $1 \mathrm{~L}$ grab samples at the breakroom sinks and water fountain locations on each floor as well as the two new sites building inlet and valve. The LuminUltra was used for this analysis (equipment: PhotonMaster/PBM Equipment Set EQPPBM-PAC; test kit: Quench Gone Aqueous QGA-100C). Samples were inverted a few times prior to analysis. The LuminUltra Quench-Gone Aqueous test kit, compliant with ASTM D4012, was used on the samples following the procedures in the test kit. ${ }^{13}$ ESI Table S10 shows the interpretation guidelines taken directly from LuminUltra as well as color coded values for the 19 grab samples.

\subsubsection{Part 4}

On the $4^{\text {th }}$ floor at a lab sink the online THM analyzer was installed which measured TTHMs hourly as well as an in-line analyzer (S::CAN con::lyte pro with chlori:: lyser free chlorine (0-20 $\mathrm{mg} / \mathrm{L}$ range), $\mathrm{pH}:$ :lyser eco, and condu::lyser) that recorded $\mathrm{pH}$, temperature, conductivity and temperature hourly. Both instruments were installed in-line with the cold water from the lab sink. To provide fresh water to both instruments, the water was not allowed to stagnate by allowing a small volume of water to constantly run through the line. The online TTHM analyzer was also used to measure the TTHM grab samples from Part 3. In-line operation of the TTHM analyzer was conducted following the instrument's instruction manual. The water to the labs is by the ICW line to comply with building codes. As discussed before, this line splits off the main domestic cold water line in the basement after the water softener and are of copper construction. The $4^{\text {th }}$ floor lab sink was selected as this lab space was seldomly used during the duration of the study and the $5^{\text {th }}$ floor lab spaces were still partially under construction, so access was limited. Therefore, the $4^{\text {th }}$ floor lab sink provided water farthest from the building inlet for 
the study. Furthermore, analyzers in the building breakrooms were undesirable as they would take up a large space creating hazards to occupants.

\subsection{Analytical and statistical methods}

Statistical methods were performed in JMP version 14. Linear regression was performed in Excel. Shapiro-Wilk W tests were conducted to determine if datasets were normally distributed. A non-parametric Steel-Dwass multiple comparisons test was conducted for first and second draw datasets by floor and fixture. Paired t-tests were conducted to compare significance between first and second draw, fixture type, and day of the week data sets. A $95 \%$ confidence interval was used for the statistical analyses. Stepwise regression using the minimum Bayesian information criterion (BIC) for model selection were conducted to determine relationships for dissolved $\mathrm{Cu}$ concentrations, cATP values, and THM concentrations with $\mathrm{R}^{2}$ adjusted analysis, linear regression of standardized data, Spearman's $\rho$ correlation, and the F ratio to determine variable influence with the F ratio reported for simplicity. Each stepwise model includes all regressors tested. To correlate free chlorine measurements to cATP and UV254 grab samples measurements, the 2,061 hourly chlorine readings from the in-line analyzer were discretized (measurements $\geq \mathrm{MDL}=1$, otherwise $=0$ ) and summed from grab sample date to grab sample date. 
Table S1: Free chlorine values for first and second draw grab samples at the water fountains. Nomenclature is floor-W-draw number where W represents water fountain.

\begin{tabular}{|c|c|c|c|c|c|c|c|c|c|c|}
\hline Date & $1-W-1$ & 2-W-1 & 3-W-1 & 4-W-1 & $5-W-1$ & $1-W-2$ & 2-W-2 & $3-W-2$ & 4-W-2 & 5-W-2 \\
\hline $5 / 29 / 2018$ & ND & ND & ND & ND & ND & ND & ND & ND & ND & ND \\
\hline 6/1/2018 & ND & ND & ND & ND & ND & ND & ND & ND & ND & ND \\
\hline 6/4/2018 & 0.02 & ND & ND & ND & ND & ND & ND & ND & ND & ND \\
\hline $6 / 7 / 2018$ & ND & ND & ND & ND & ND & ND & ND & ND & ND & ND \\
\hline $6 / 11 / 2018$ & ND & ND & ND & ND & ND & ND & 0.02 & 0.02 & 0.04 & ND \\
\hline $6 / 14 / 2018$ & ND & ND & ND & ND & ND & ND & ND & ND & ND & ND \\
\hline $6 / 18 / 2018$ & ND & ND & ND & ND & ND & ND & ND & ND & ND & ND \\
\hline $6 / 21 / 2018$ & ND & ND & ND & ND & ND & ND & ND & ND & ND & ND \\
\hline $6 / 25 / 2018$ & ND & ND & ND & ND & ND & ND & ND & ND & ND & $\mathrm{ND}$ \\
\hline $6 / 28 / 2018$ & ND & ND & ND & ND & ND & ND & ND & ND & ND & ND \\
\hline $7 / 2 / 2018$ & ND & ND & ND & ND & ND & ND & ND & ND & ND & ND \\
\hline $7 / 9 / 2018$ & ND & ND & ND & ND & ND & ND & ND & ND & ND & ND \\
\hline $7 / 12 / 2018$ & ND & ND & ND & ND & ND & ND & ND & ND & ND & ND \\
\hline $7 / 16 / 2018$ & ND & ND & ND & ND & ND & ND & ND & ND & ND & ND \\
\hline $7 / 19 / 2018$ & ND & ND & ND & ND & ND & ND & ND & ND & ND & ND \\
\hline $7 / 23 / 2018$ & ND & ND & ND & ND & ND & ND & ND & ND & ND & 0.03 \\
\hline $7 / 26 / 2018$ & ND & ND & ND & ND & ND & ND & ND & ND & ND & ND \\
\hline $7 / 30 / 2018$ & ND & ND & ND & ND & ND & ND & ND & ND & ND & ND \\
\hline $8 / 2 / 2018$ & 0.02 & ND & ND & ND & ND & ND & ND & ND & ND & ND \\
\hline $8 / 6 / 2018$ & ND & ND & ND & ND & ND & ND & ND & ND & ND & ND \\
\hline $8 / 9 / 2018$ & ND & ND & ND & ND & ND & ND & ND & ND & ND & ND \\
\hline $8 / 13 / 2018$ & ND & ND & ND & ND & ND & ND & ND & ND & ND & ND \\
\hline $8 / 16 / 2018$ & 0.02 & ND & ND & ND & ND & ND & ND & ND & ND & ND \\
\hline $8 / 20 / 2018$ & ND & ND & ND & ND & ND & ND & ND & ND & ND & ND \\
\hline $8 / 23 / 2018$ & ND & ND & ND & ND & ND & ND & ND & ND & ND & ND \\
\hline $8 / 27 / 2018$ & ND & ND & ND & ND & ND & ND & ND & ND & ND & ND \\
\hline $8 / 30 / 2018$ & ND & ND & ND & ND & ND & ND & ND & ND & ND & ND \\
\hline 9/6/2018 & ND & ND & ND & ND & ND & ND & ND & ND & ND & ND \\
\hline $9 / 10 / 2018$ & 0.02 & ND & ND & ND & ND & 0.02 & ND & ND & ND & 0.02 \\
\hline 9/13/2018 & ND & ND & ND & ND & ND & ND & ND & ND & ND & ND \\
\hline $9 / 20 / 2018$ & ND & ND & ND & ND & ND & ND & 0.10 & ND & ND & ND \\
\hline $9 / 24 / 2018$ & ND & ND & ND & ND & ND & ND & ND & ND & ND & ND \\
\hline $9 / 27 / 2018$ & ND & ND & ND & ND & ND & ND & ND & ND & ND & ND \\
\hline $10 / 1 / 2018$ & ND & ND & ND & ND & ND & ND & ND & ND & ND & ND \\
\hline $10 / 4 / 2018$ & ND & ND & ND & ND & ND & ND & ND & ND & ND & ND \\
\hline $10 / 11 / 2018$ & ND & ND & ND & ND & ND & ND & ND & ND & ND & ND \\
\hline $10 / 15 / 2018$ & ND & ND & ND & ND & ND & ND & ND & ND & ND & ND \\
\hline $10 / 18 / 2018$ & ND & ND & ND & ND & ND & ND & ND & ND & ND & ND \\
\hline
\end{tabular}


Table S2. Stepwise models relating WTP water quality parameters to THM species with F ratios and $\mathrm{p}$ values for significant variables.

\begin{tabular}{r|cccc}
\multicolumn{5}{c}{ Species } \\
\hline Parameter & BF & DBCM & DCBM & CF \\
\hline WTP averaged effluent chloride & $29.4, \mathrm{p}<0.0001$ & $47.1, \mathrm{p}<0.0001$ & $13.8, \mathrm{p}<0.0001$ & $2.95, \mathrm{p}<0.0001$ \\
Average WTP Temp (C) & $2.4, \mathrm{p}=0.12453$ & $12.5, \mathrm{p}=0.0004$ & $2.1, \mathrm{p}<0.0001$ & $98.5, \mathrm{p}<0.0001$ \\
Average WTP TOC & $27.9, \mathrm{p}<0.0001$ & $33.8, \mathrm{p}<0.0001$ & $181.8, \mathrm{p}<0.0001$ & $60.8, \mathrm{p}<0.0001$ \\
\hline $\mathrm{R}^{2}$ adjusted & 0.25 & 0.8 & 0.83 & 0.66 \\
\hline
\end{tabular}


Table S3. The number of times reported as percent, a fixture by floor measured above US EPA primary and secondary MCL for the duration of the study (May 2018 - April 2019). The naming convention for location is floor-fixture where B represents breakroom and $\mathrm{W}$ represents water fountain.

\begin{tabular}{ccc}
\hline Location & $\begin{array}{c}\text { Primary MCL } \\
1.3 \mathrm{mg} / \mathrm{L}\end{array}$ & $\begin{array}{c}\text { Secondary } \\
\text { MCL } 1.0 \mathrm{mg} / \mathrm{L}\end{array}$ \\
\hline 1-B & $0 \%$ & $9 \%$ \\
2 -B & $4 \%$ & $7 \%$ \\
3-B & $0 \%$ & $9 \%$ \\
4-B & $3 \%$ & $12 \%$ \\
5-B & $4 \%$ & $8 \%$ \\
$1-\mathrm{W}$ & $26 \%$ & $47 \%$ \\
2-W & $8 \%$ & $24 \%$ \\
$3-\mathrm{W}$ & $11 \%$ & $28 \%$ \\
$4-\mathrm{W}$ & $28 \%$ & $47 \%$ \\
$5-\mathrm{W}$ & $20 \%$ & $41 \%$ \\
\hline
\end{tabular}


Table S4. Cellular adenosine triphosphate (cATP) values for breakroom sinks and water fountains where naming convention is floor-Breakroom sink or Water fountain - first draw. Only the first draw was measured to capture what an occupant would be exposed to if the occupant used the water immediately without flushing the line. Building inlet is a hose bib closest to the meter prior to the whole building water softener.

\begin{tabular}{|c|c|c|c|c|c|c|c|c|c|c|c|}
\hline Date & 1-B-1 & 2-B-1 & 3-B-1 & 4-B-1 & 5-B-1 & 1-W-1 & 2-W-1 & 3-W-1 & 4-W-1 & 5-W-1 & Building Inlet \\
\hline $2 / 4 / 2019$ & 3.97 & 25.41 & 0.16 & 1.27 & 1.02 & 11.61 & 3.78 & 2.19 & 3.24 & 3.87 & 0.06 \\
\hline 2/7/2019 & 7.18 & 23.37 & 0.54 & 0.41 & 0.68 & 4.94 & 0.48 & 0.46 & 5.00 & 4.15 & 0.02 \\
\hline $2 / 11 / 2019$ & 3.5 & 15.00 & 0.11 & 0.43 & 0.81 & 6.19 & 0.94 & 0.51 & 8.36 & 9.06 & 0.09 \\
\hline $2 / 14 / 2019$ & 2.9 & 1.99 & 0.14 & 0.29 & 0.41 & 4.32 & 0.39 & 0.35 & 5.25 & 4.19 & 0 \\
\hline $2 / 18 / 2019$ & 15.52 & 13.5 & 1.19 & 2.99 & 2.51 & 8.48 & 1.45 & 2.01 & 5.28 & 4.79 & 0 \\
\hline $2 / 21 / 2019$ & 8.63 & 3.95 & 0.3 & 1.43 & 4.29 & 5.24 & 0.48 & 1.12 & 5.74 & 3.54 & 0 \\
\hline $2 / 25 / 2019$ & 7.3 & 6.23 & 0.8 & 1.4 & 3.66 & 10.34 & 7.3 & 5.42 & 10.89 & 10.93 & \\
\hline $2 / 28 / 2019$ & 4.64 & 3.5 & 0.41 & 3.24 & 0.96 & 8.63 & 1.22 & 1.8 & 5.41 & 13.38 & 0.01 \\
\hline $3 / 11 / 2019$ & 12.06 & 9.52 & 4.97 & 5.71 & 10.27 & 15.06 & 10.62 & 5.24 & 16.21 & 7.29 & 0.05 \\
\hline $3 / 14 / 2019$ & 9.41 & 4.78 & 1.06 & 12.4 & 6.17 & 7.89 & 5.99 & 2.34 & 9.12 & 12.55 & 0.01 \\
\hline $3 / 18 / 2019$ & 12.31 & 4.36 & 3.62 & 9.21 & 4.82 & 16.63 & 7.63 & 8.01 & 12.73 & 14.74 & 0.03 \\
\hline $3 / 21 / 2019$ & 5.46 & 6.63 & 1.66 & 5.36 & 4.58 & 7.42 & 3.63 & 2.38 & 12.59 & 14.54 & 0.03 \\
\hline $3 / 25 / 2019$ & 27.73 & 11.65 & 7.42 & 13.24 & 25.64 & 11.06 & 13.17 & 11.85 & 17.51 & 15.77 & 0.3 \\
\hline $3 / 28 / 2019$ & 3.19 & 2.27 & 1.02 & 4.41 & 3.72 & 6.79 & 3.58 & 1.51 & 4.09 & 5.43 & 0.09 \\
\hline 4/8/2019 & 11.63 & 4 & 3.9 & 9.94 & 6.73 & 13.75 & 6.87 & 7.24 & 9.26 & 13.27 & 0 \\
\hline $4 / 11 / 2019$ & 6.2 & 8.53 & 2.78 & 4.35 & 4.79 & 10.79 & 6.66 & 3.17 & 7.19 & 19.14 & 0 \\
\hline $4 / 15 / 2019$ & 6.41 & 4.84 & 2.52 & 6.62 & 5.03 & 15.27 & 7.78 & 4.6 & 13.88 & 8.8 & 0.49 \\
\hline $4 / 25 / 2019$ & 17.72 & 11.01 & 3.16 & 9.32 & 7.42 & 15.23 & 11.37 & 6.89 & 16.15 & 19.11 & 0 \\
\hline $4 / 29 / 2019$ & 33.8 & 15.7 & 6.78 & 9.7 & 11 & 19.59 & 12.06 & 11.92 & 18.19 & 21.83 & 0.46 \\
\hline $\begin{array}{c}<1 \mathrm{pg} \\
\mathrm{cATP} / \mathrm{mL}\end{array}$ & $0 \%$ & $0 \%$ & $37 \%$ & $16 \%$ & $21 \%$ & $0 \%$ & $21 \%$ & $16 \%$ & $0 \%$ & $0 \%$ & \\
\hline $\begin{array}{c}>1 \mathrm{pg} \\
\mathrm{cATP} / \mathrm{mL}\end{array}$ & $100 \%$ & $100 \%$ & $63 \%$ & $84 \%$ & $79 \%$ & $100 \%$ & $79 \%$ & $84 \%$ & $100 \%$ & $100 \%$ & \\
\hline
\end{tabular}




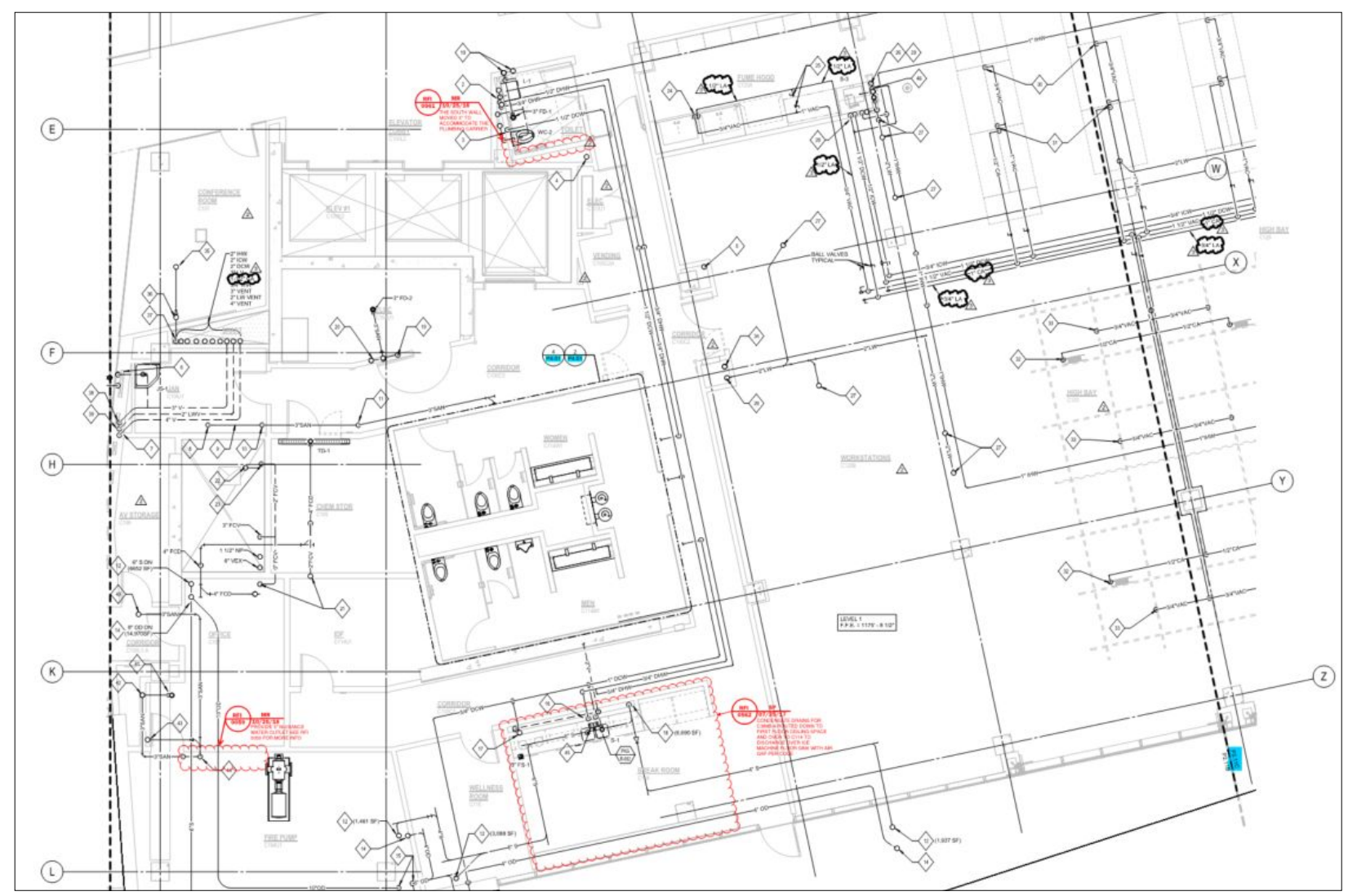

Figure S1: Plumbing plan for the $1^{\text {st }}$ floor showing alcove with two water fountains adjacent to each other. The DCW riser is located behind the water fountains. When facing the fountains, fountain on the right was sampled on each floor. The $1^{\text {st }}$ floor breakroom is at the bottom of the figure. 


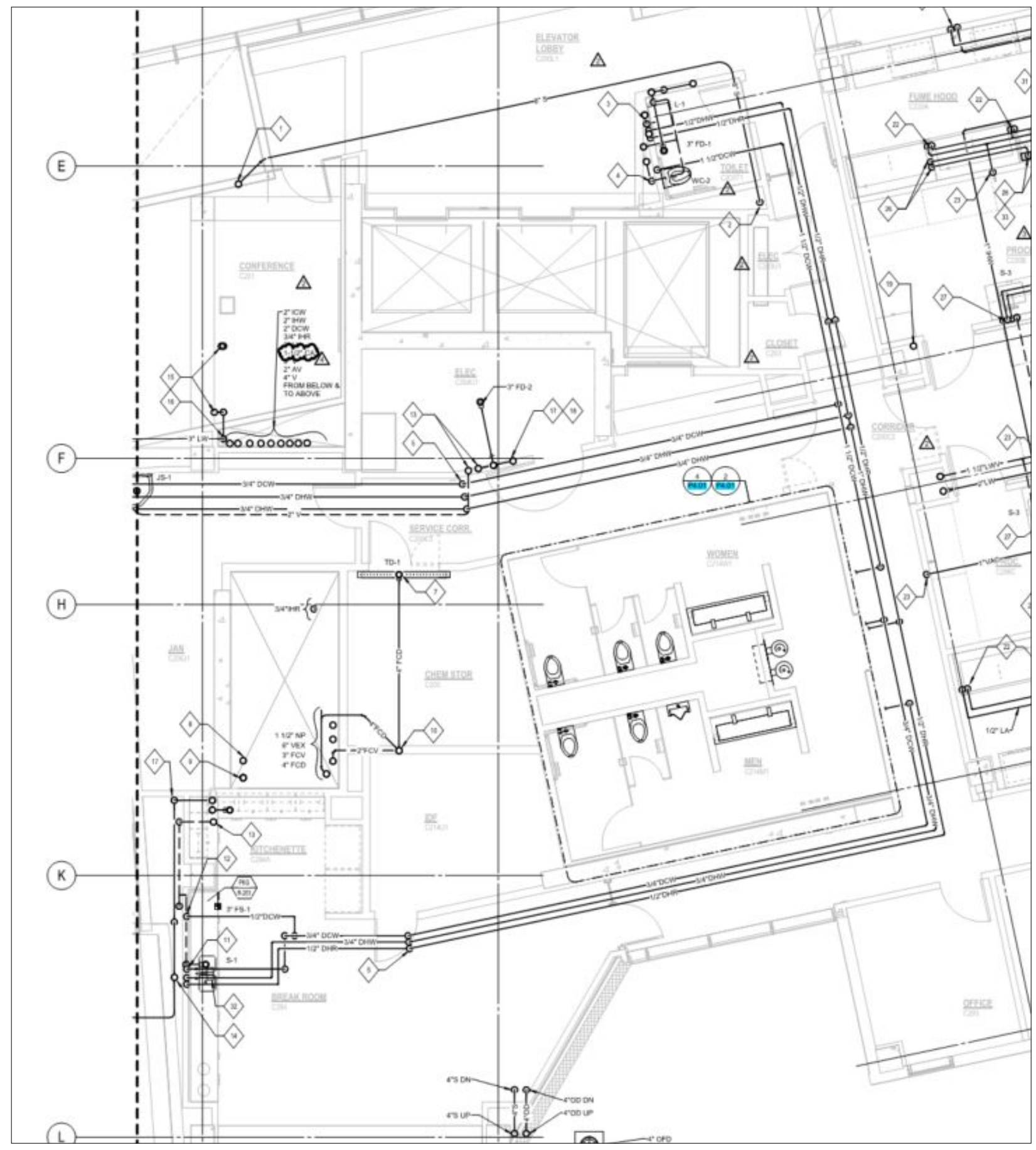

Figure S2: Plumbing plan for the $2^{\text {nd }}$ floor. The restrooms are stacked directly on top of each floor so the water fountain location will not change. The breakroom of each floor is also stacked on top of each other. However, the $1^{\text {st }}$ and $2^{\text {nd }}$ floor have the sinks located in slightly different locations. The $3^{\text {rd }}-5^{\text {th }}$ floors have identical floor plans shown in Figure S3. 


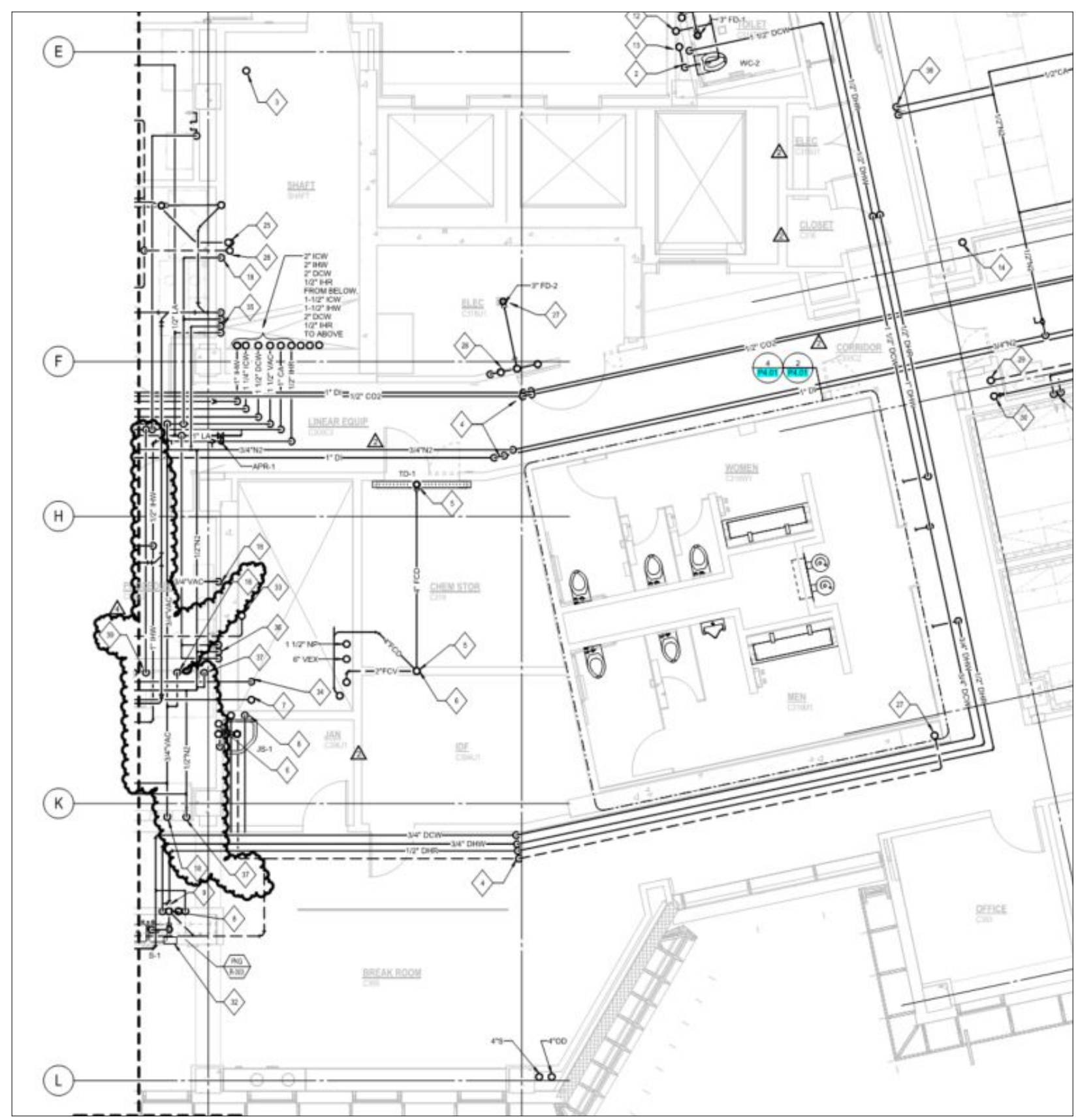

Figure S3: The $3^{\text {rd }}-5^{\text {th }}$ floor breakrooms are identical as shown in this plumbing plan. 


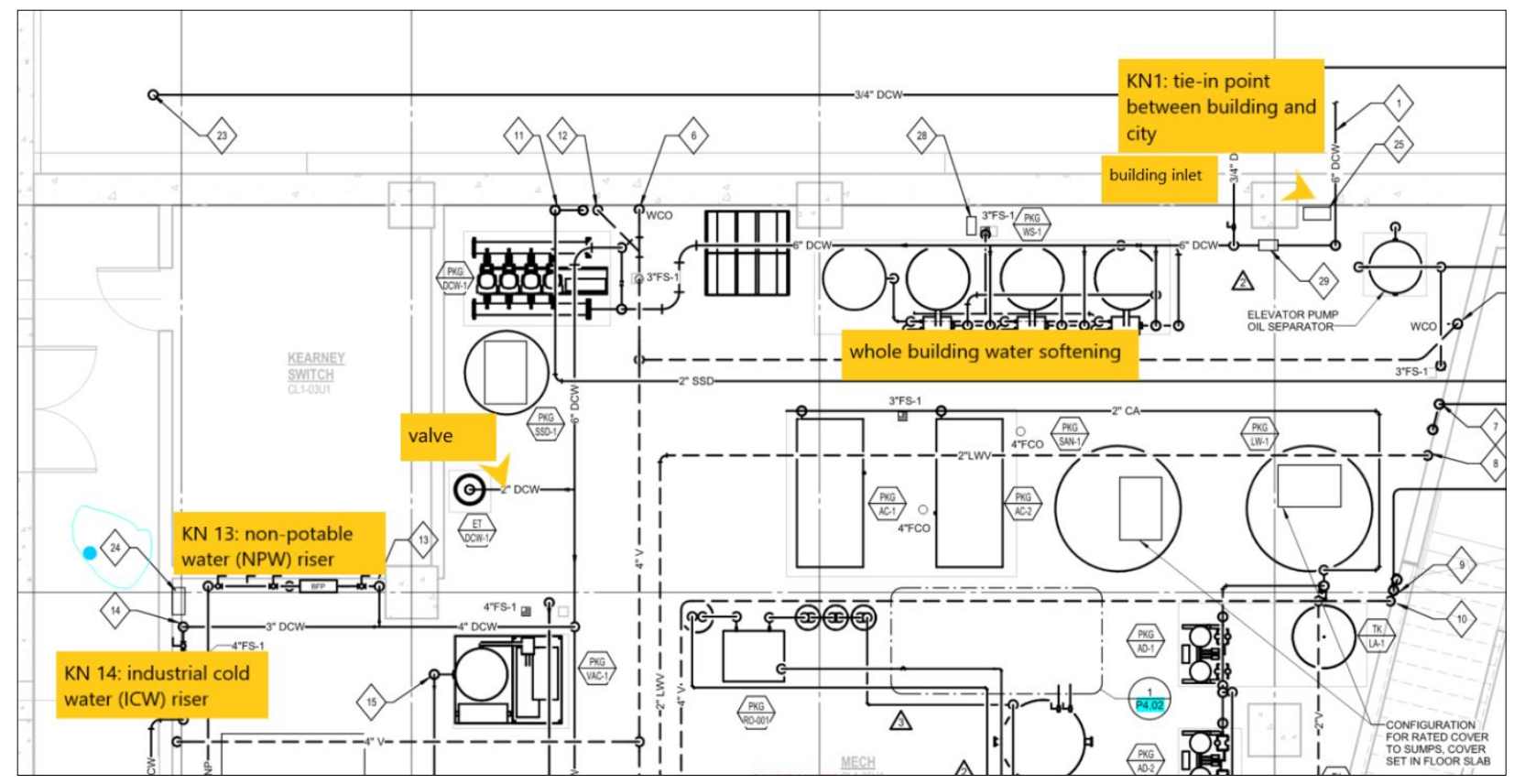

Figure S4: Mechanical room drawing showing the building inlet and valve sampling locations with yellow arrows. Keyed notes (KN) from the drawing set are diamond shapes and are called out to show building tie-in (KN1), non-potable water (NPW) riser (KN13), and industrial cold water (ICW) riser (KN14). The DCW riser is shown in Figure S5 as the riser is behind the alcove and originates in the basement outside of the mechanical room. The whole building water softener has also been notated. All risers are fed from the 6" DCW main which is part of KN1. 

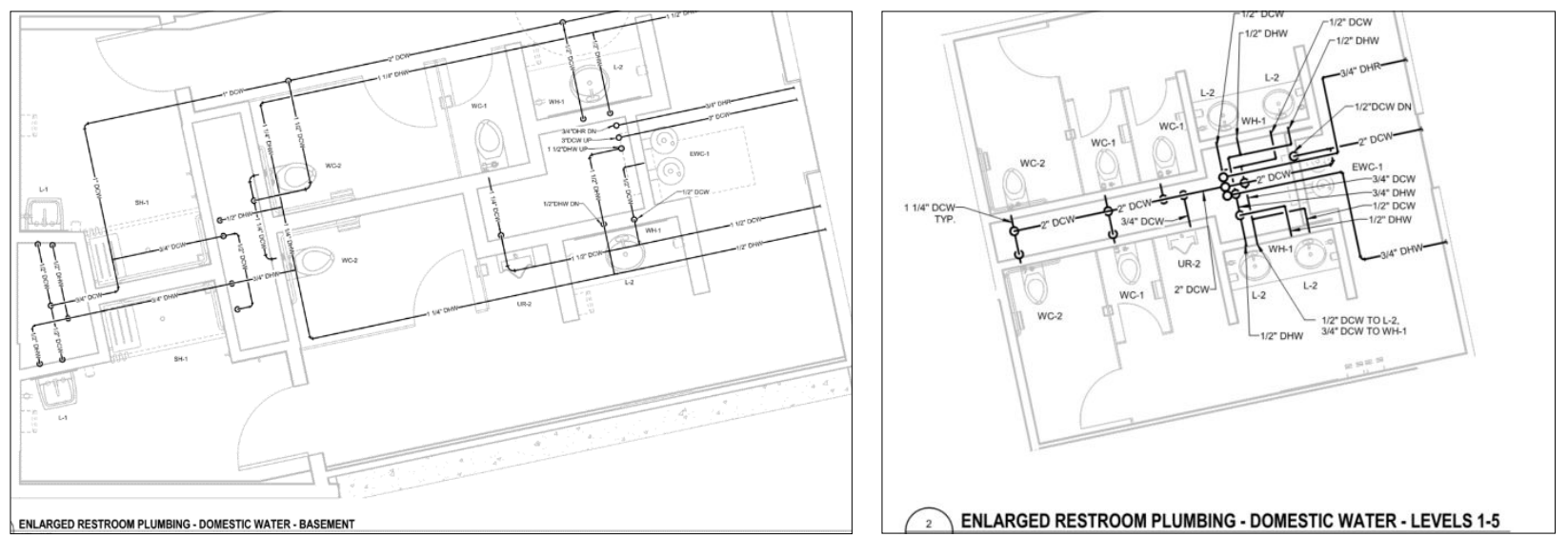

Figure S5: Domestic cold water (DCW) riser feeding breakrooms, bathrooms, and water fountains is located behind the alcove. This riser originates in the basement. 


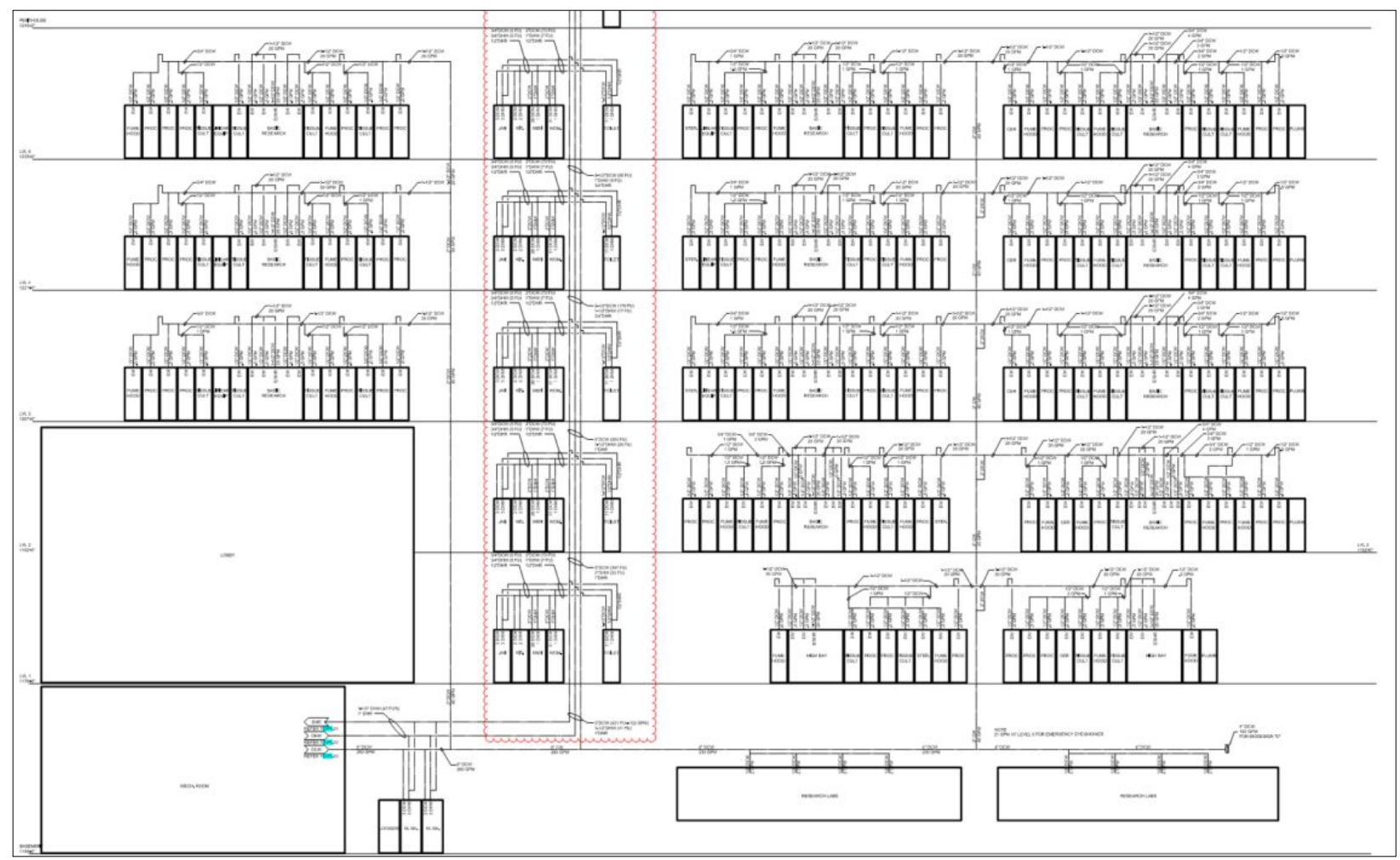

Figure S6: Domestic cold water (DCW) riser, starting in the basement, feeds the stacked bathrooms and breakrooms on all 5 floors. 


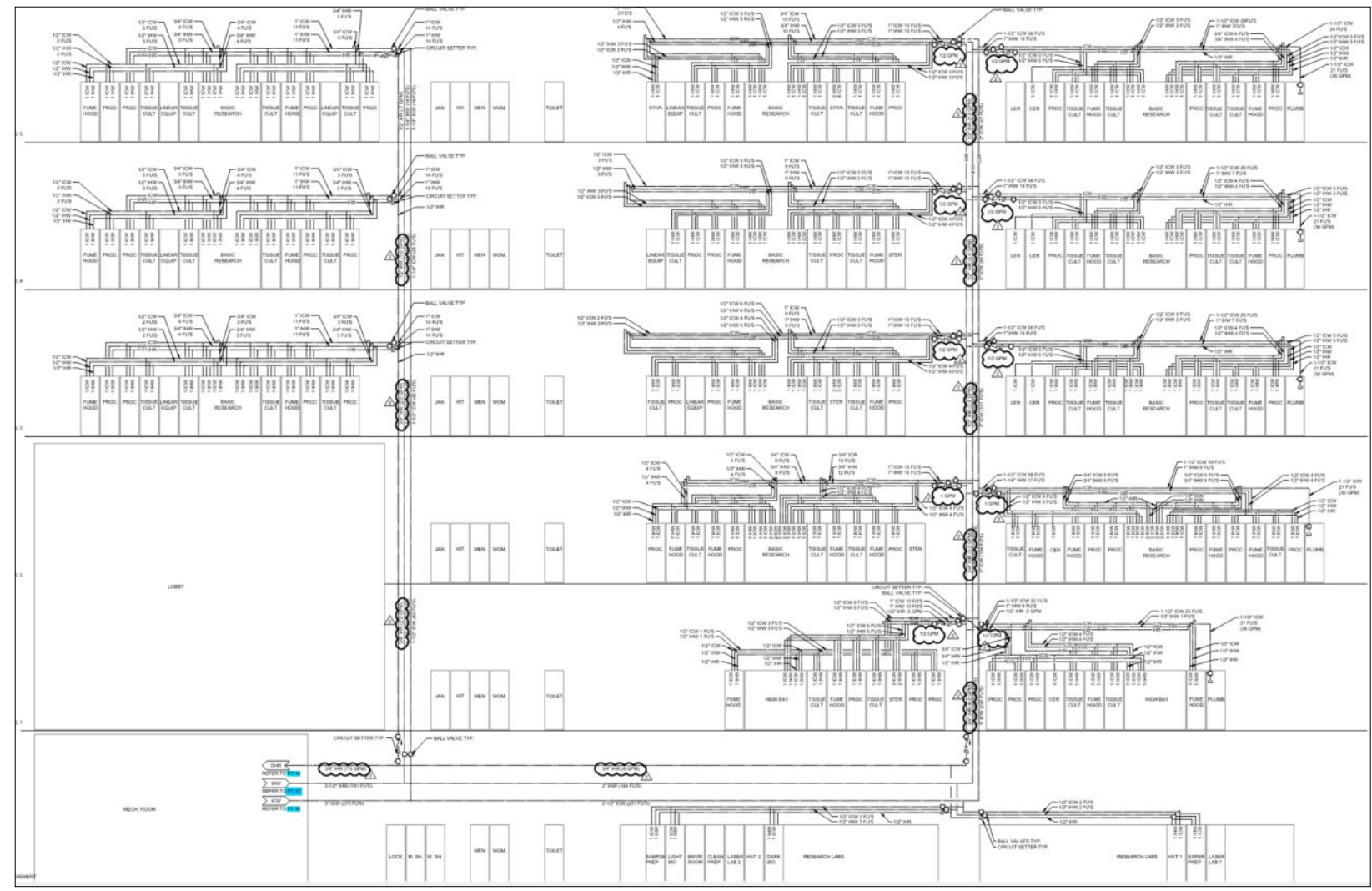

Figure S7: Industrial cold water (ICW) riser starts in the basement in the mechanical room, fed by the domestic cold water (DCW) main and feeds areas such as lab spaces. 


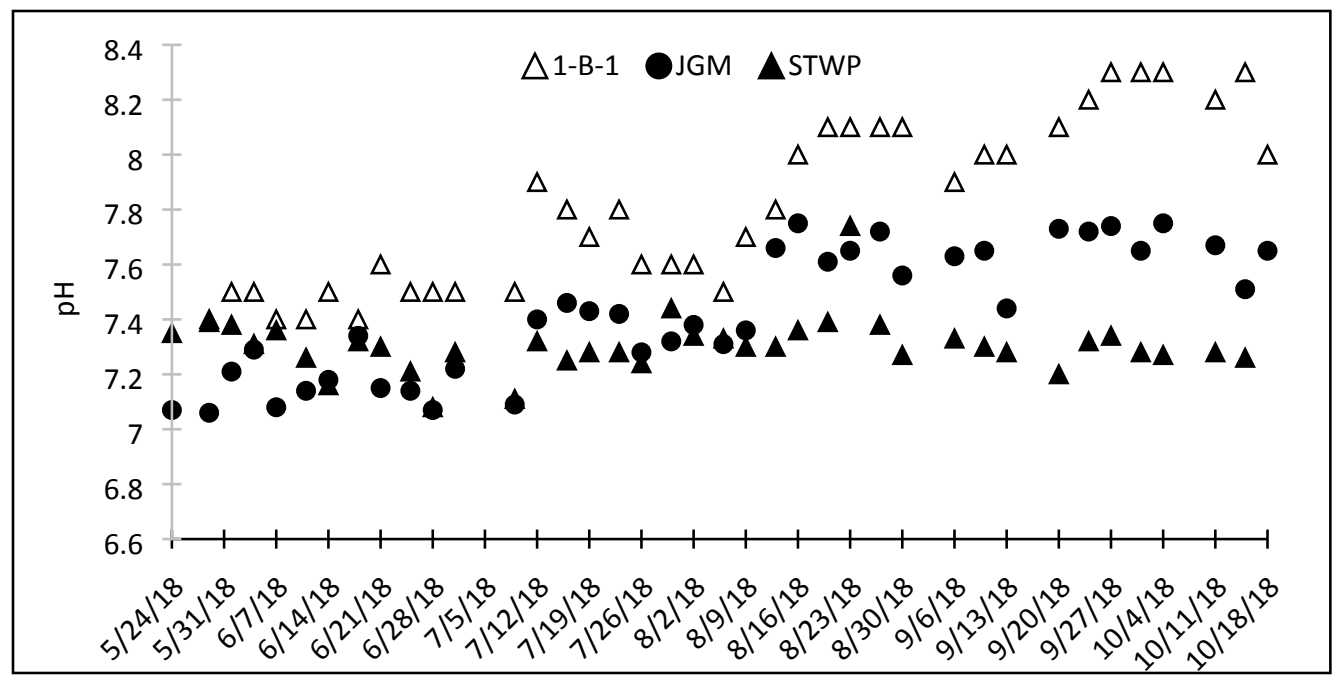

Figure S8: Building $\mathrm{pH}$ at the 1st floor, first draw, breakroom sink versus both WTPs. 


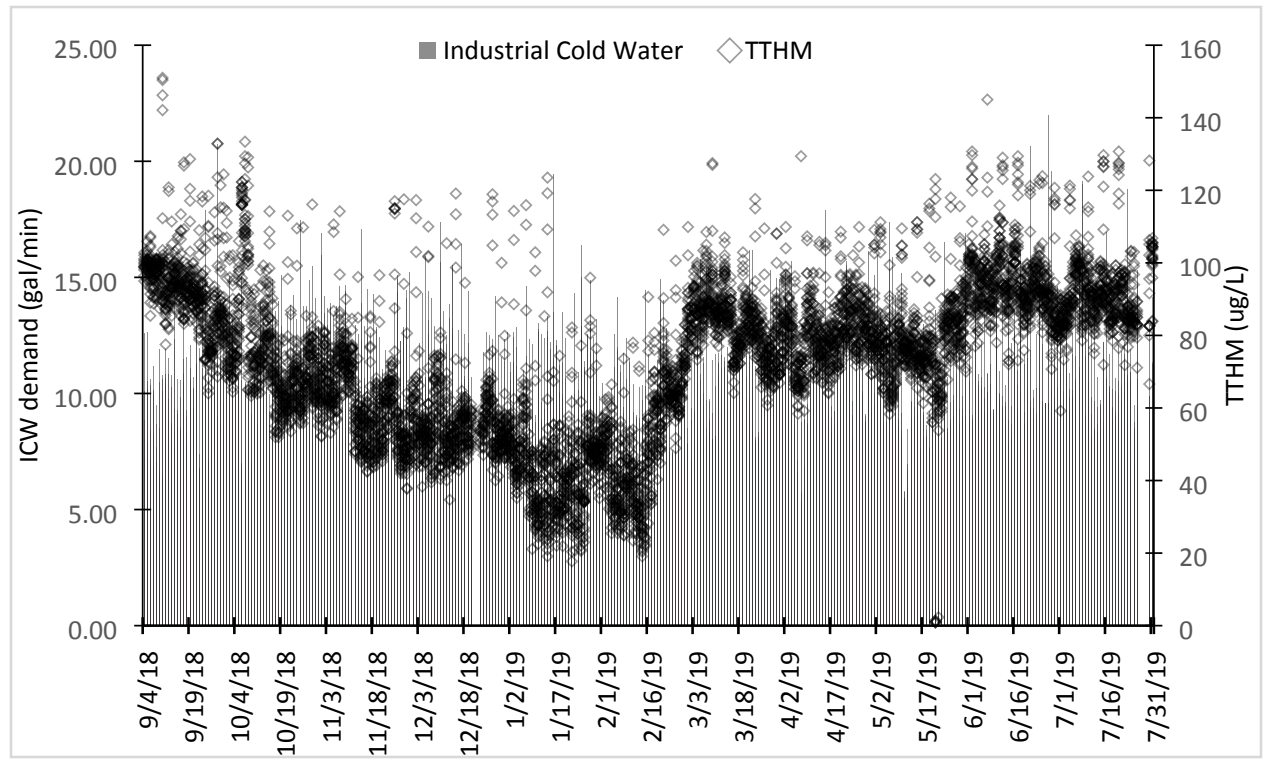

Figure S9. Hourly total trihalomethane (TTHM) readings plotted against hourly industrial cold water (ICW) flow meter readings. The reading duration is over a 10 -month period selected to match when the in-line analyzer and TTHM analyzer were online and reading at the same time. 


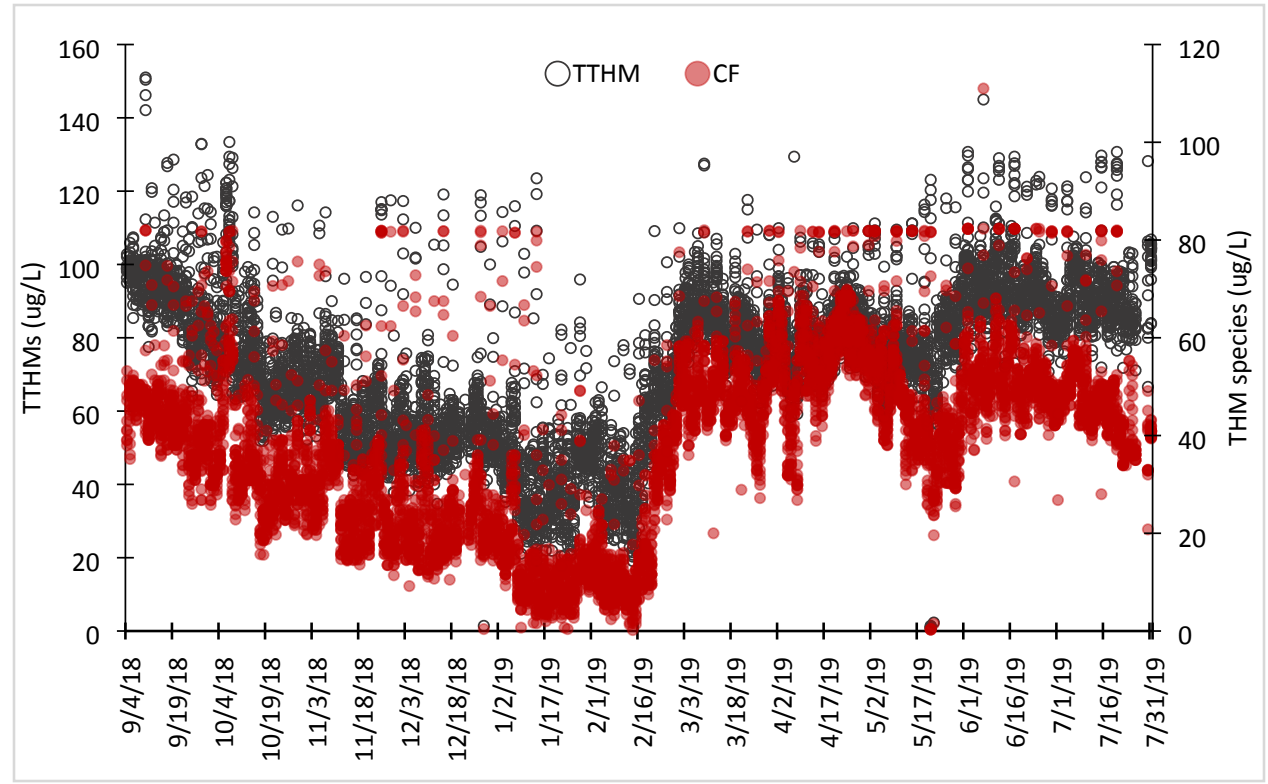

Figure S10: Hourly online THM analyzer readings for chloroform (CF) speciation vs total trihalomethanes (TTHM) from September 2018 - July 2019. 


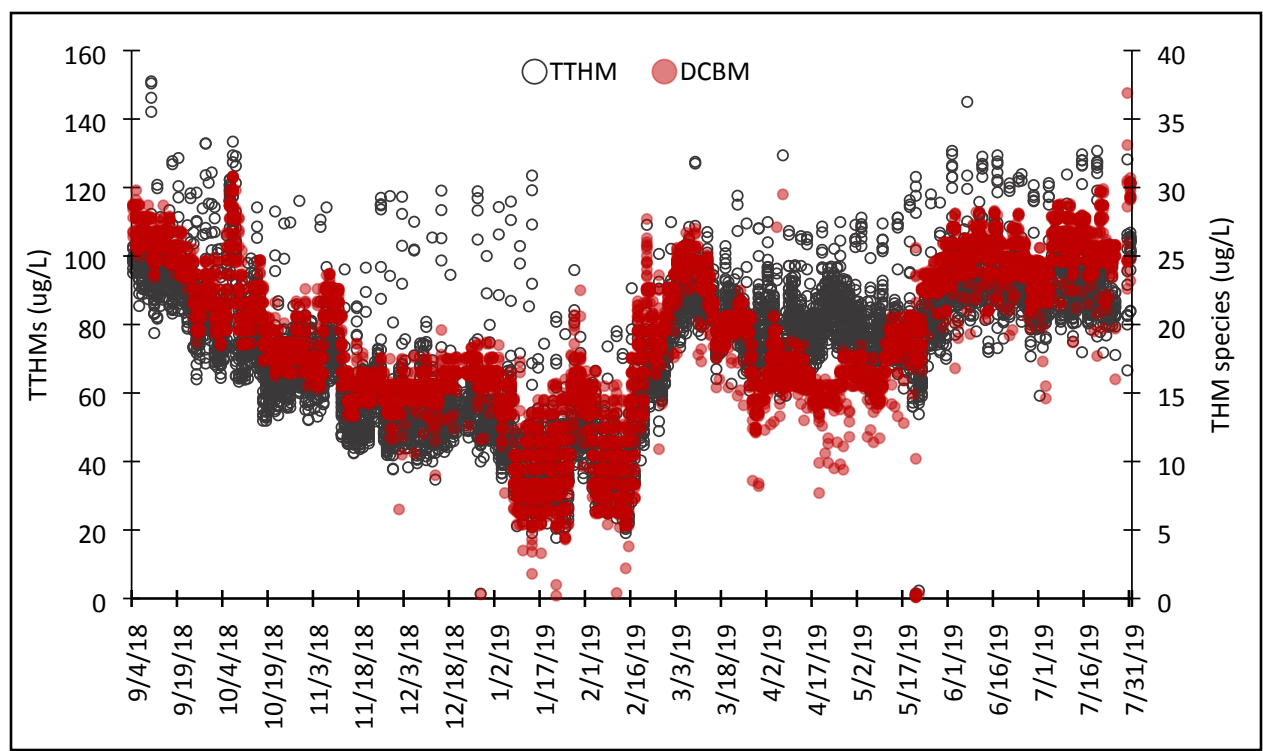

Figure S11: Hourly online THM analyzer readings for dichlorobromoform (DCBM) speciation vs total trihalomethanes (TTHM) from September 2018 - July 2019. 


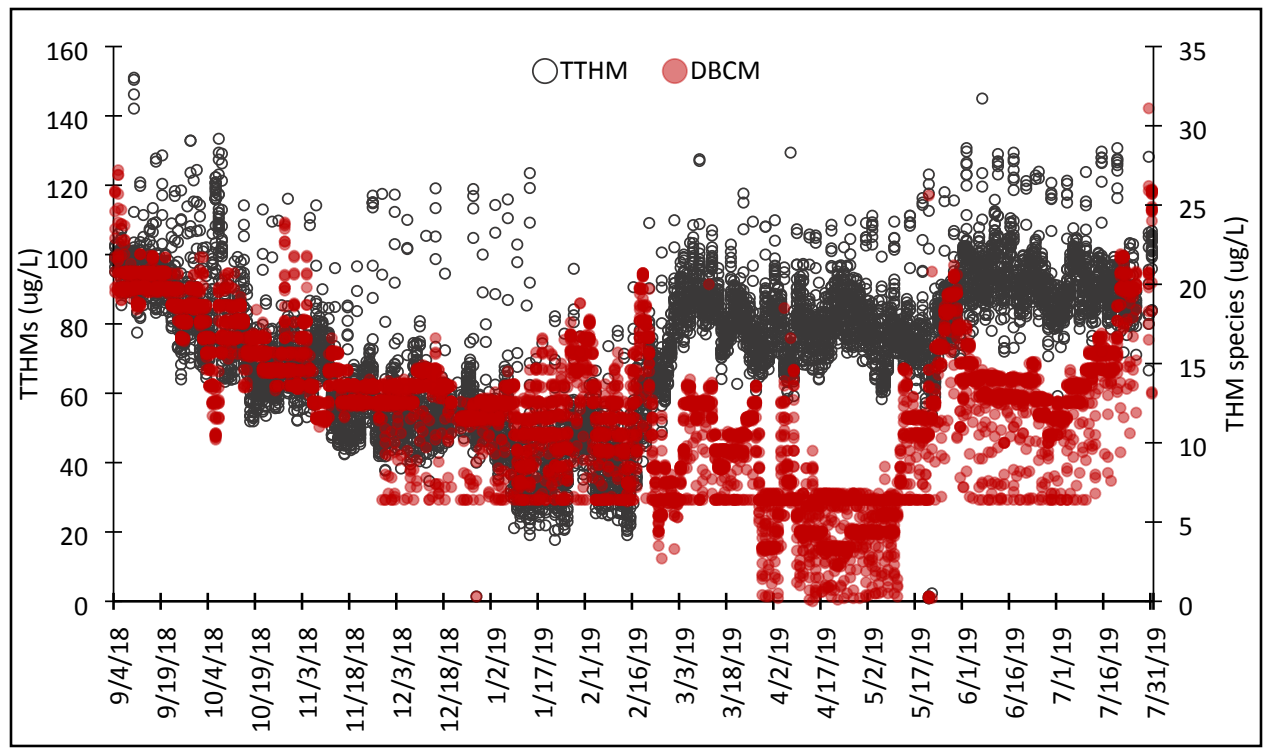

Figure S12: Hourly online THM analyzer readings for dibromochloromethane (DBCM) speciation vs total trihalomethanes (TTHM) from September 2018 - July 2019. 


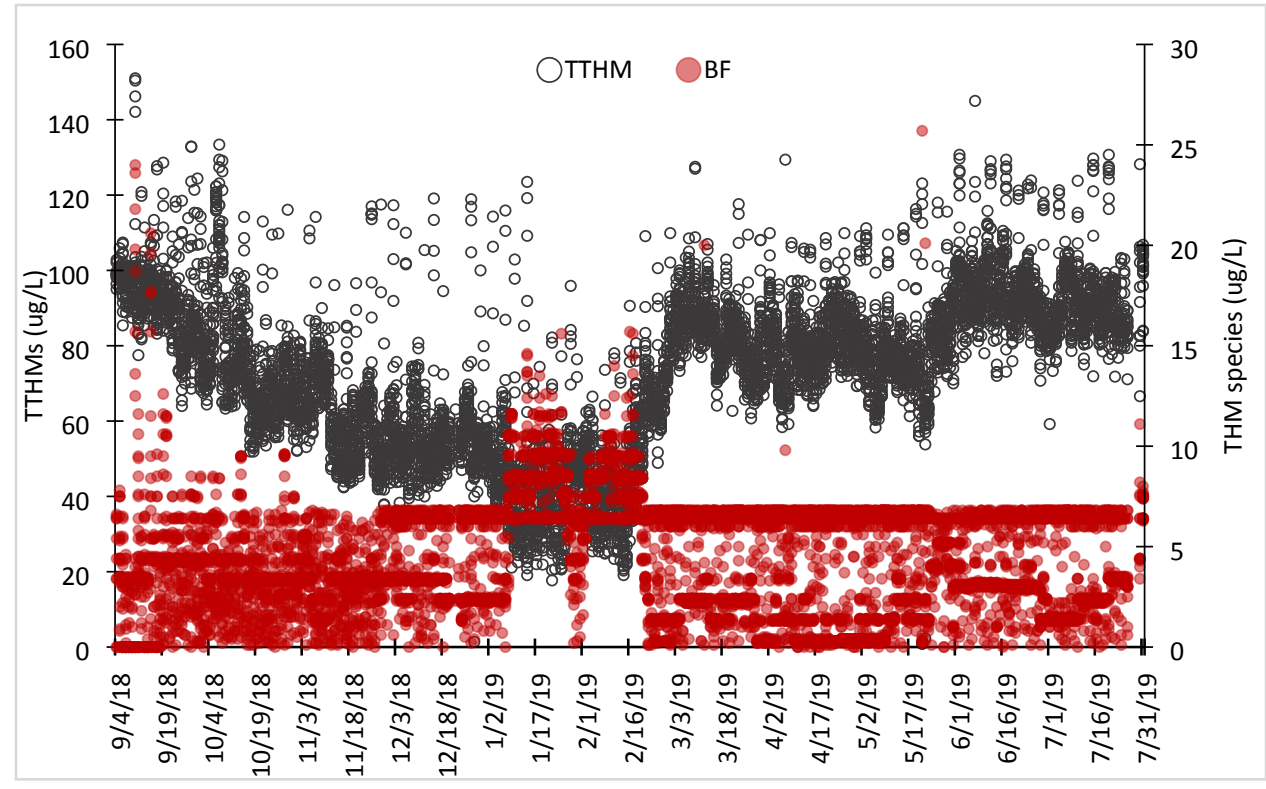

Figure S13: Hourly online THM analyzer readings for bromoform (BF) speciation vs total trihalomethanes (TTHM) from September 2018 - July 2019. 


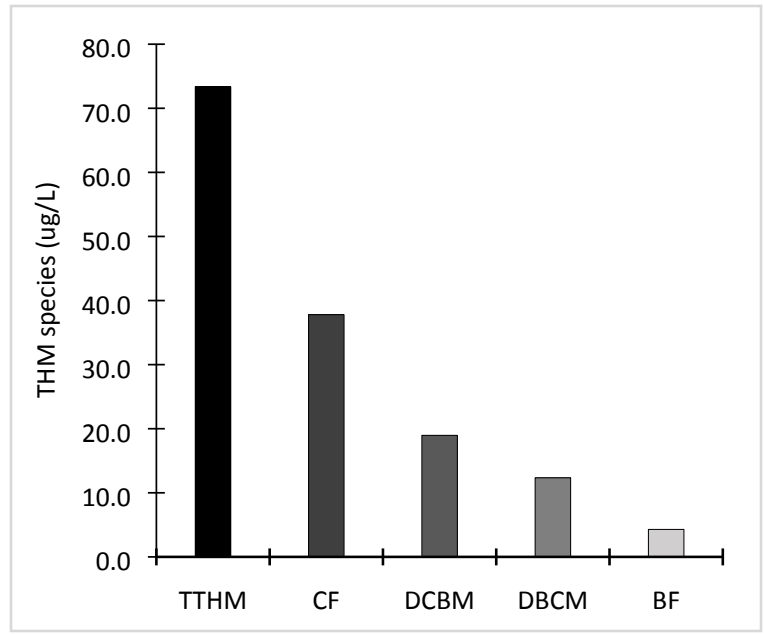

Figure S14. The averaged values of hourly trihalomethane speciation readings; chloroform (CF), dichlorobromoform (DCBM), dibromochloromethane (DBCM), and bromoform (BF), from September 2018 - July 2019 by the THM analyzer located in the $4^{\text {th }}$ floor lab. 

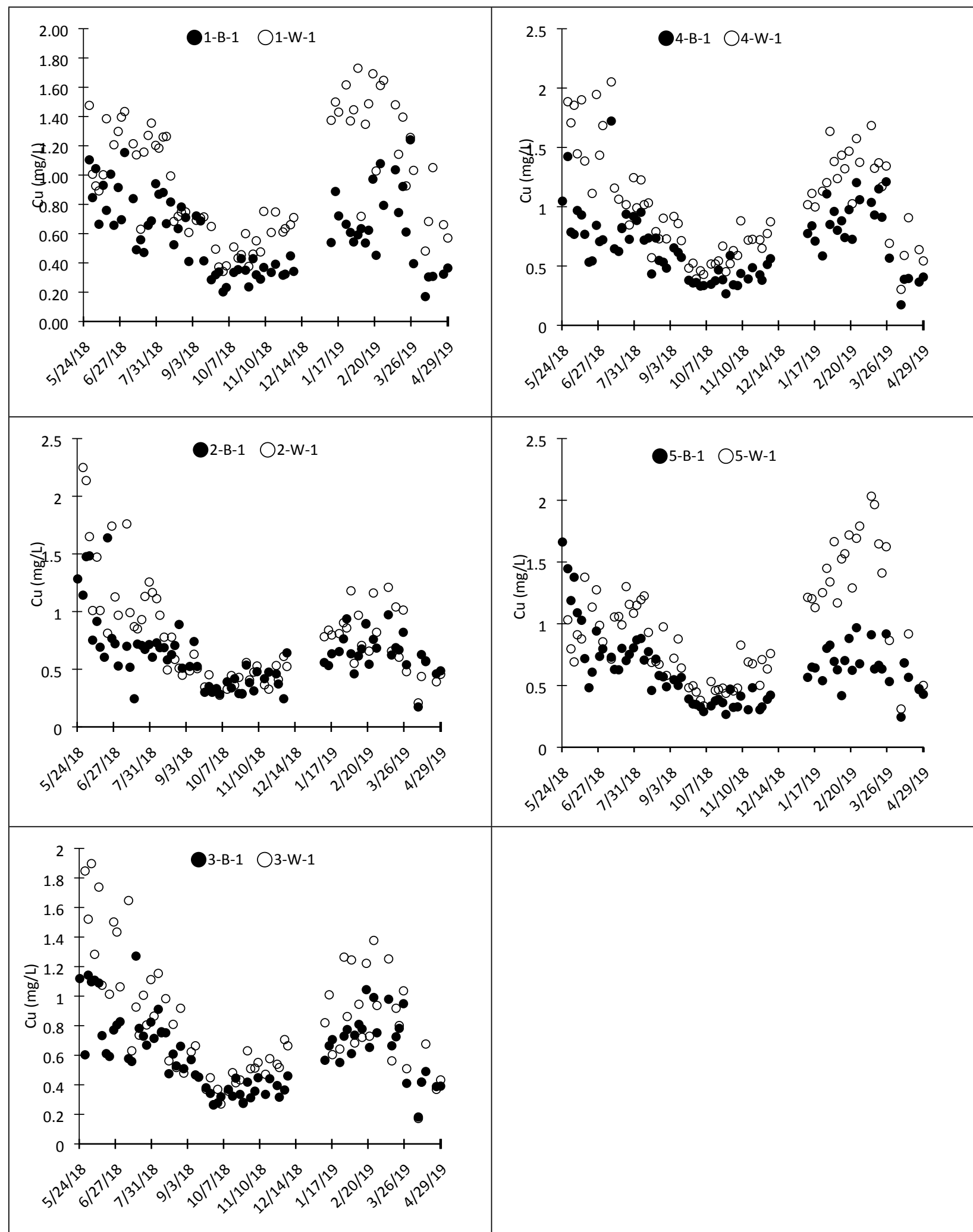

Figure S15: Breakroom sink and water fountain copper values for immediate first draw grab samples. Sampling was from May 2018 - April 2019. Nomenclature is floor-fixture-draw number where B represents breakroom and $\mathrm{W}$ water fountain. The break in data is due to winter break. 


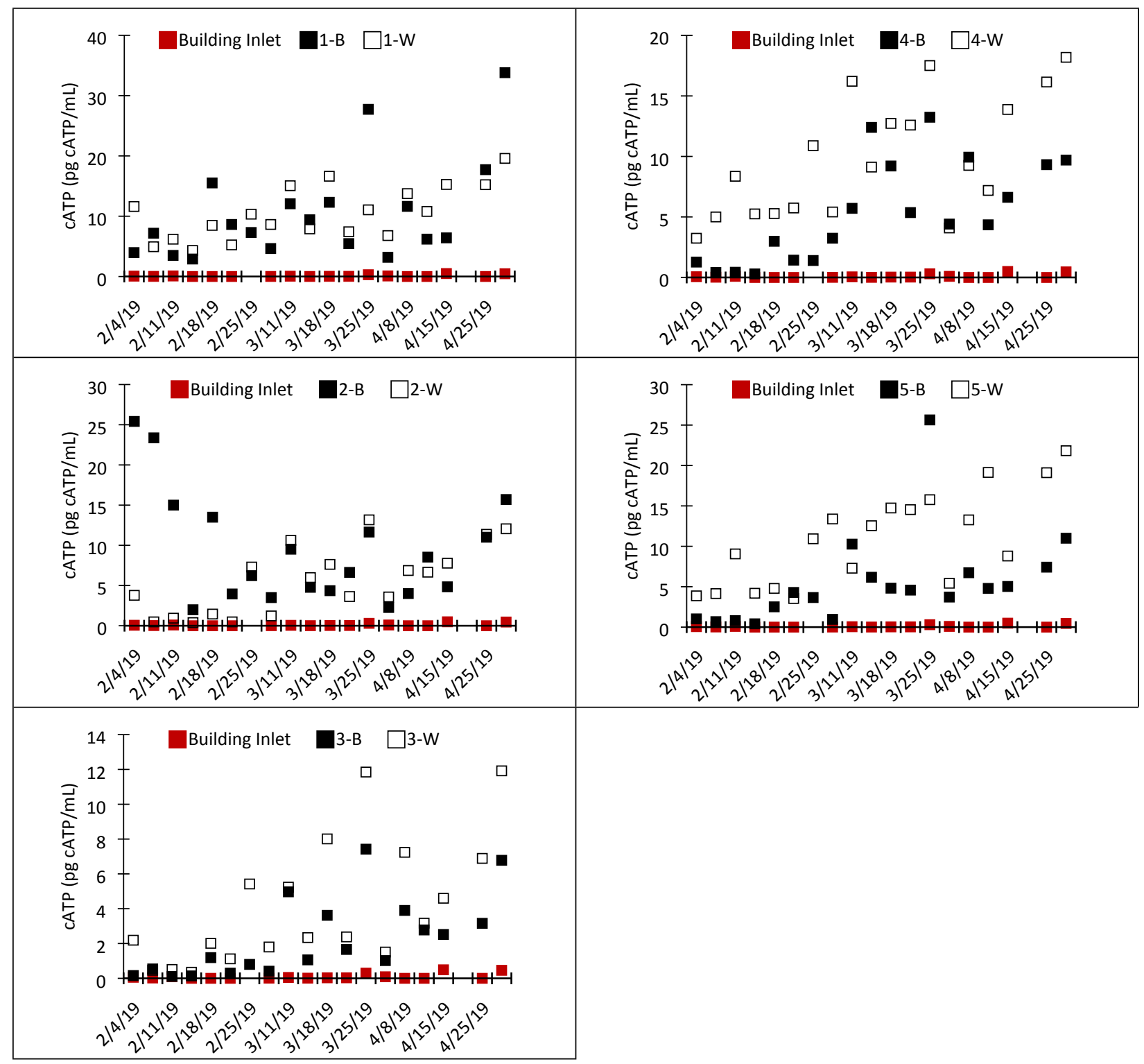

Figure S16: cATP values on each floor comparing the building inlet to the breakroom sink and water fountain. Building inlet consistently had the lowest cATP values. 


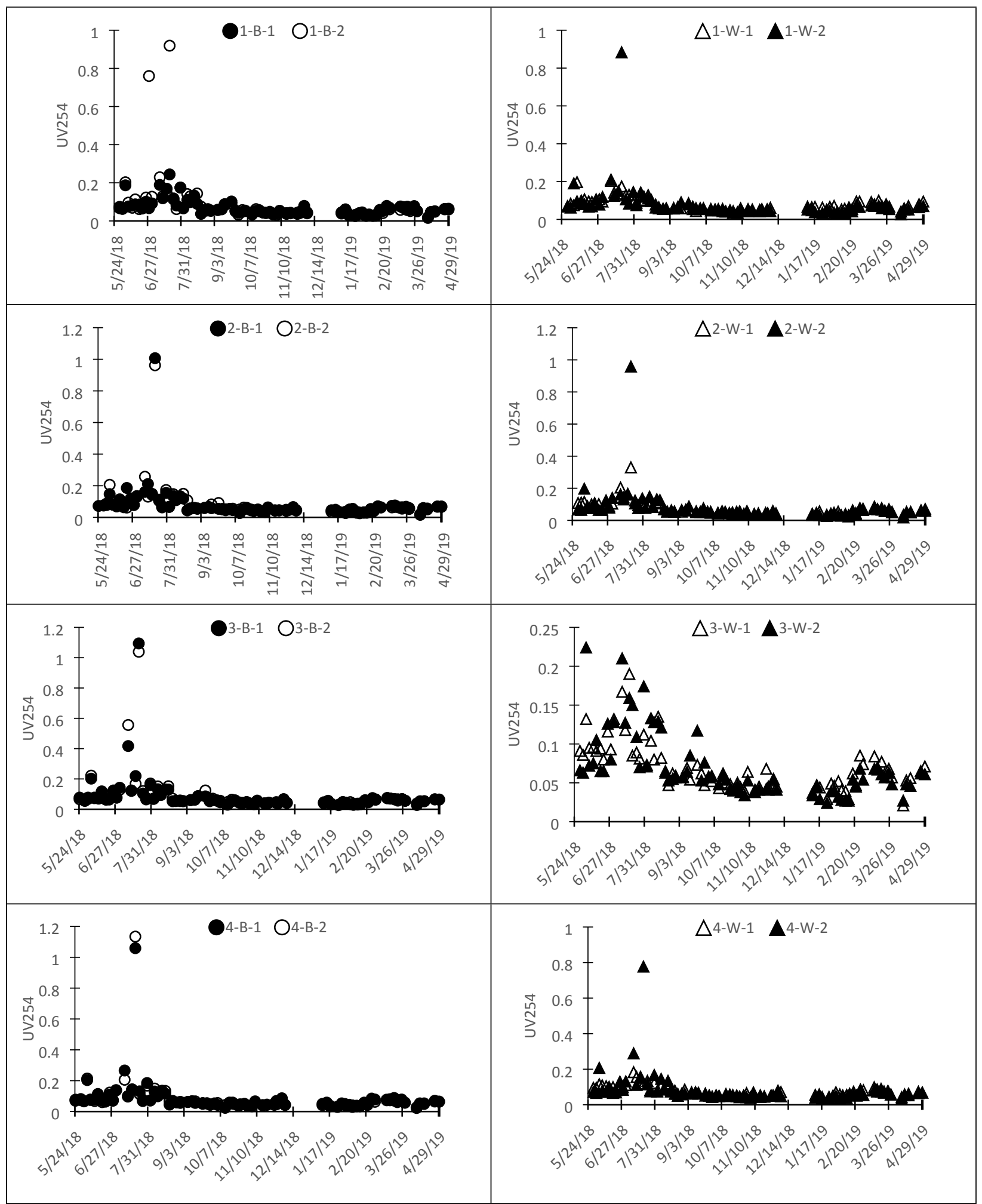




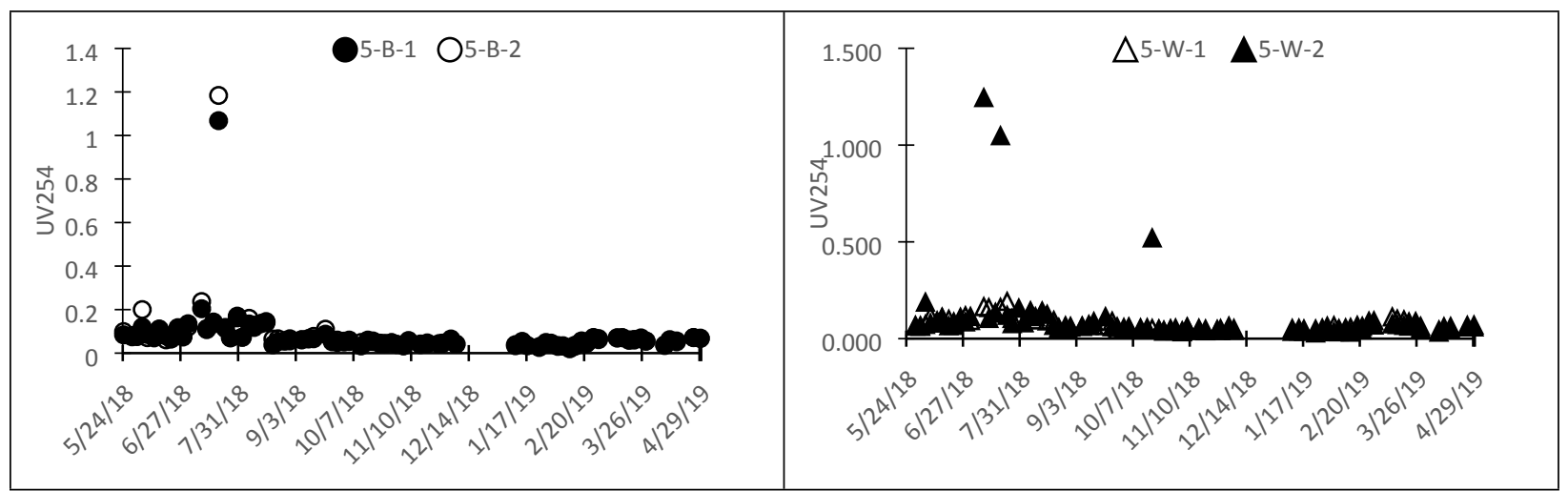

Figure S17a: UV254 values from grab samples for duration of study May 2018 - April 2019. Grab samples were for each floor, at the breakroom sink and water fountain. Nomenclature is floor - fixture - draw where B is for breakroom and $\mathrm{W}$ is for water fountain. Figure S17b shows the same graph but without the spike event for better detail. 


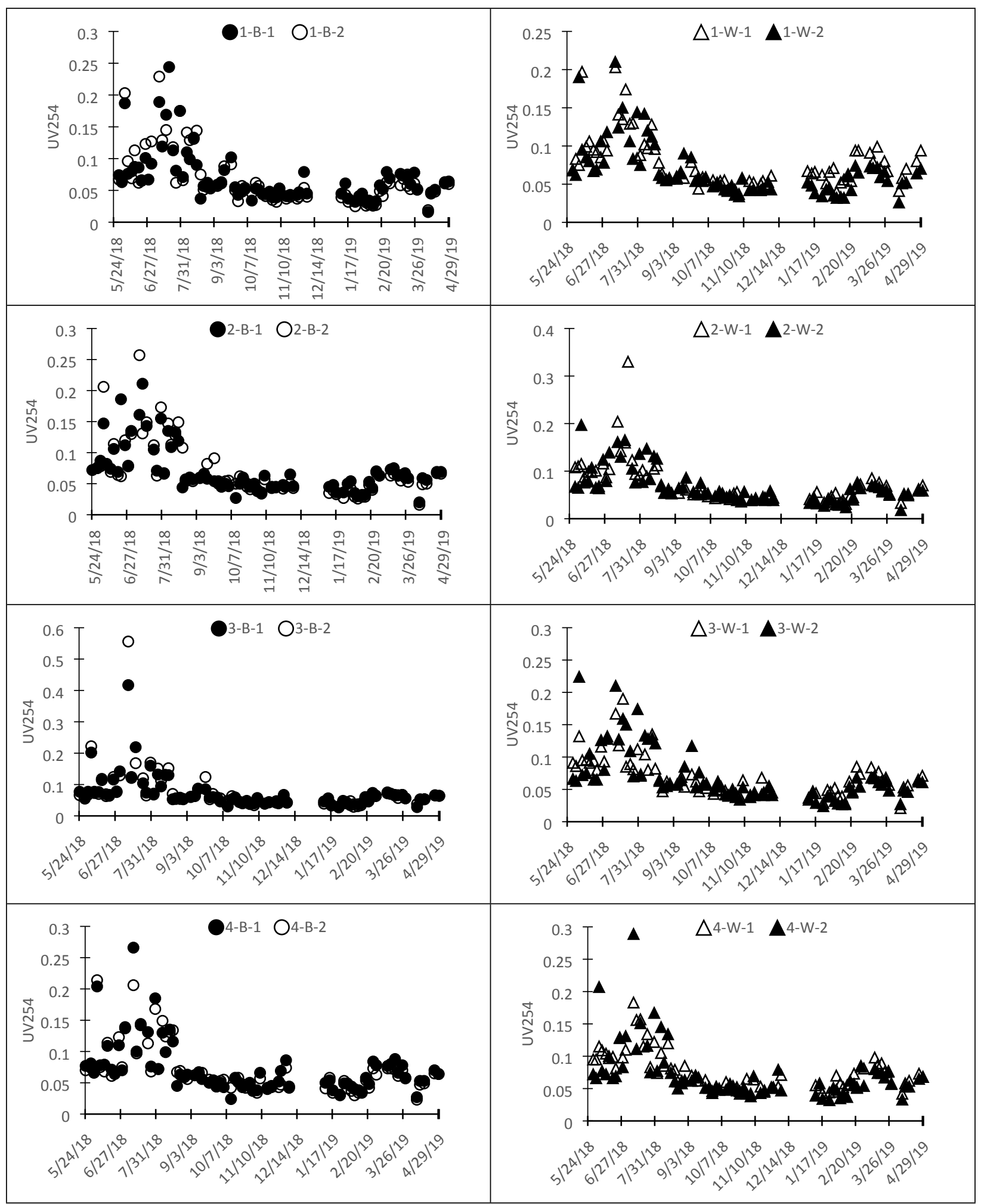




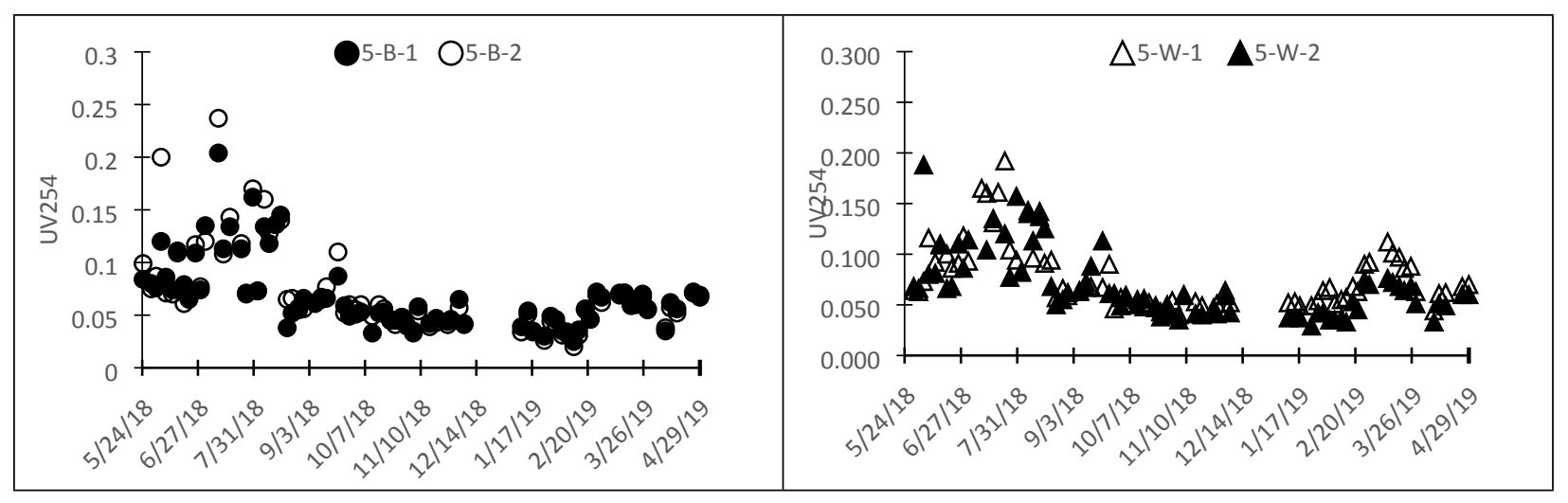

Figure S17b: Same graph as Figure S17a shown without the spike event for visualization of other trends.

S30 